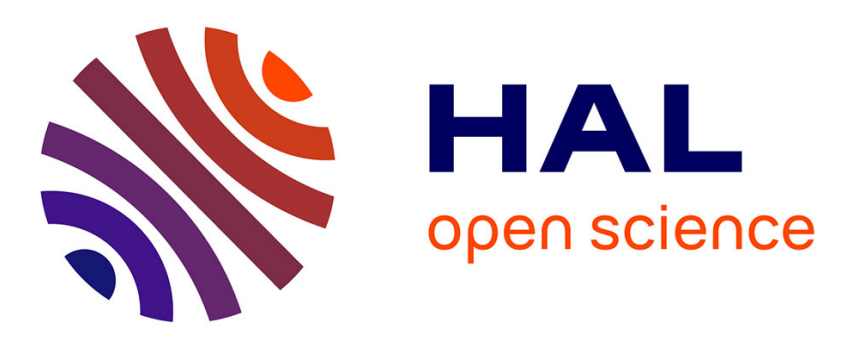

\title{
A FTIR/chemometrics approach to characterize the gamma radiation effects on iodine/epoxy-paint interactions in Nuclear Power Plants
}

Elodie Chauvet, Sandrine Amat, Nathalie Dupuy, Didier Gigmes, Juliette Colombani

\section{To cite this version:}

Elodie Chauvet, Sandrine Amat, Nathalie Dupuy, Didier Gigmes, Juliette Colombani. A FTIR/chemometrics approach to characterize the gamma radiation effects on iodine/epoxypaint interactions in Nuclear Power Plants. Analytica Chimica Acta, 2017, 960, pp.53-62. 10.1016/j.aca.2017.01.005 . hal-01493747

\section{HAL Id: hal-01493747 https://hal.science/hal-01493747}

Submitted on 12 Apr 2018

HAL is a multi-disciplinary open access archive for the deposit and dissemination of scientific research documents, whether they are published or not. The documents may come from teaching and research institutions in France or abroad, or from public or private research centers.
L'archive ouverte pluridisciplinaire HAL, est destinée au dépôt et à la diffusion de documents scientifiques de niveau recherche, publiés ou non, émanant des établissements d'enseignement et de recherche français ou étrangers, des laboratoires publics ou privés. 


\title{
A FTIR/chemometrics approach to characterize the gamma radiation effects on iodine/epoxy-paint interactions in Nuclear Power Plants
}

\author{
Juliette Colombani ${ }^{\mathrm{a},}{ }^{*}$, Elodie Chauvet ${ }^{\mathrm{a}, \mathrm{c}}$, Sandrine Amat ${ }^{\mathrm{b}}$, Nathalie Dupuy ${ }^{\mathrm{b}}$, \\ Didier Gigmes ${ }^{c}$ \\ a Institut de Radioprotection et de Sûreté Nucléaire, PSN-RES/SEREX/L2EC, CEN Cadarache BP3, 13115 Saint Paul lez Durance Cedex, France \\ ${ }^{\mathrm{b}}$ Aix-Marseille Université, CNRS, IRD, Avignon Université, IMBE UMR 7263, 13397 Marseille Cedex 20, France \\ ${ }^{\mathrm{c}}$ Aix-Marseille Université, CNRS ICR UMR 7273, 13397 Marseille Cedex 20, France
}

\section{G R A P H I C A L A B S T R A C T}

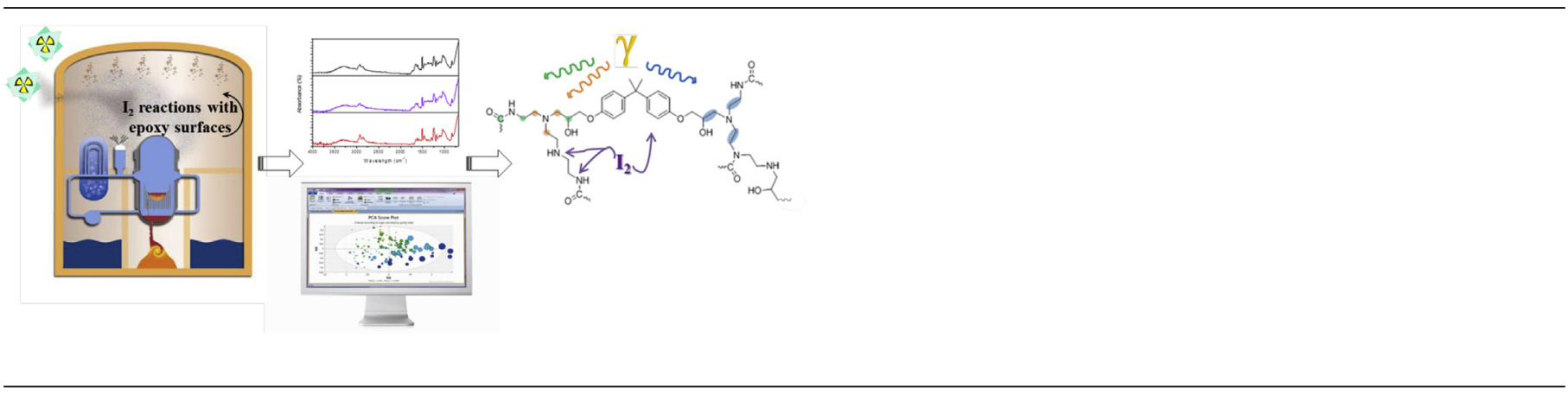

\section{A B S T R A C T}

Keywords:

MIR spectroscopy

AComDim

Epoxy-paint

Iodine

Gamma radiation
The effects of radiation on polymeric materials are a topic of concern in a wide range of industries including the sterilization, and the nuclear power industry. While much work has concentrated on systems like polyolefins that are radiation sterilized, some work has been done on epoxy systems. The epoxy system studied is an epoxy/amine paint which is representative of the paint that covers the inner surfaces of the French nuclear reactor containment buildings. In case of a severe accident on a Nuclear Power Plant, fission products can be released from the nuclear fuel to the reactor containment building. Among them, volatile iodine $\left(\mathrm{I}_{2}\right)$ can be produced and can interact with the epoxy-paint. This paint is also subjected to gamma radiation damages (due to the high dose in the containment coming from radionuclides released from the fuel). So the epoxy-paint studied was exposed to gamma radiation under air atmosphere after being loaded with $\mathrm{I}_{2}$ or not.

The aim of this study is to characterize by FTIR spectroscopy the iodine-paint interactions, then to identify the radiation damages on the epoxy-paint, and to check their effects on these iodine-paint interactions. This work shows the potential of multi-block analysis method (ANOVA-PCA and COMDIM $=$ AComDim) for such a study as it allows to identify the nature of iodine/epoxy-paint interactions and to characterize the gamma radiation damages on the epoxy-paint. AComDim method conduces to the extraction of Common Components to different tables and highlights factors of influence and their interactions. 


\section{Introduction}

In the event of a loss-of-coolant accident in a Nuclear Power Plant (NPP), leading to reactor core melt-down, fission products can be released from the nuclear fuel up to the reactor containment building. Among them, iodine is one of the most hazardous radionuclides because of its radiotoxicity and its ability to form volatile species. The amount and kinetics of iodine release to the environment due to containment leakages or containment venting procedure following the accident highly depends on its volatility in the containment. The evolution of the volatile iodine concentration in the containment is thus of main concern. It is determined by a balance between formation and deposition or destruction processes. The understanding of these processes considerably evolved after the performance of the series of Phébus Fission Products integral tests that were undertaken to investigate key phenomena involved in NPP severe accidents and particularly the iodine chemistry in the containment [1-4]. Phébus test results showed that iodine may enter the containment in gaseous and particulate forms in various proportions depending on the accident conditions [5-8]. Then, deposition processes occur in the containment (on inner surfaces, mostly epoxy-painted surfaces, in the sump) which reduces the overall airborne iodine concentration. After some couple of hours, the containment airborne iodine concentration reaches a steady state level, lower than concentration levels observed during the early stage of the accident.

Current assumptions to explain the rather fast disappearance of the gaseous iodine amount observed on the very short term of the accidental phase in Phébus tests are largely based on chemical interactions of gaseous molecular iodine $\left(\mathrm{I}_{2}\right)$ with epoxy-painted surfaces of the containment [9-12]. The iodine/Epoxy-paint interactions under radiation started to be studied in the sixties [13] and has gained and gained in importance in the $1990^{\prime}$ and later on [14-18]. Funke has developed an iodine-paint model in 1999 [19] with Marchand's data [20] to reproduce the iodine/Epoxypaint behaviour under radiation. However, it does not fit well all the data in this area and large discrepancies still exist.

The aim of the present work is to study the Iodine/epoxy-paint interactions under radiation by Fourier Transform Mid-InfraRed Attenuation Total Reflectance (MIR-ATR). The experimental approach consists in characterizing the epoxy-paint before and after being exposed to radiation (gamma-ray), studying the radiation damages by identifying the chemical and functional modifications in the epoxy-paint, and checking their effect on the iodinepaint interactions. The influence of several parameters on the evolution of epoxy-paint MIR-ATR spectra was thus studied: the irradiation dose and the presence of iodine loaded on the epoxypaint. Infrared spectra were used as responses of full factorial experimental design, built taking into account two factors: the gamma irradiation dose and iodine presence or not (the design is balanced).

The influence of the different experimental factors, as well as their interactions, were simultaneously analyzed using a multivariate analysis technique, the AComDim method [21]. This method for the detection of significant factors has been applied to spectral datasets from a variety of samples, e.g., wine, to study the influence of the vintage (year), maceration method and/or microoxygenation; apple, to study the influence of the cultivar and the maturity; starch-lignin mixtures, to study humidity, shape and lignin content [21]. This method has also been used to study the effects of experimental factors on the quality of spectral responses for commercial diesel [22]. In contrast to the ANOVA-PCA method [23], AComDim replaces successfully the separate PCAs with a single analysis to give an evaluation of significance of the effects [24.].

\section{Materials and methods}

\subsection{Epoxy-paint samples}

The paint studied was obtained by curing the Diglycidyl ether of bisphenol A (DGEBA)-based epoxy prepolymer with a polyamidoamine (PAA) adduct. All the reactants were purchased from Freitag ${ }^{\circledR}$ and used without any further purification. To obtain the epoxypaint, a mixture of $36 \mathrm{vol} \%$ of DGEBA and $64 \mathrm{vol} \%$ of PAA were blended at room temperature and deposited on a Teflon mould. After $24 \mathrm{~h}$ of drying under an extractor hood, the polymer obtained is a thin film of $(85 \pm 10) \mu \mathrm{m}$ of thickness and it has a tridimensional network structure with the reticulation point located on the nitrogen atom of the amine adduct (see Fig. 3) [25]. The samples were then stored protected from light.

\section{2. $I_{2}$ loading of epoxy-paint samples}

The process of Iodine loading is performed on the device presented in Fig. 1. A mass of $50 \mathrm{mg}$ of iodine pellets is introduced into tank 1 at ambient pressure and temperature. Then tank 1 is tightly closed and covered with an aluminum foil in order to prevent the decomposition of $I_{2}$ by UV ambient radiation. The epoxy-paint samples are placed in tank 2 . Then tank 2 is tightly closed and drawn under vacuum. Tanks 1 and 2 are connected by opening the separating valves V3 and V4. In these conditions solid iodine sublimates (due to its low saturation vapor pressure) and gaseous iodine is released and transferred to tank 2 (tank 2 is also covered with an aluminum foil for the reasons done above). The gaseous $\mathrm{I}_{2}$ is kept in contact with the epoxy-paint samples during $16 \mathrm{~h}$. After the loading phase, tank 2 is swept by Argon to transfer the residual quantity of $\mathrm{I}_{2}$ atmosphere to the $\mathrm{NaOH}$ trap. The epoxy-paint samples are recovered and exhibit a light brown color. The values of concentration of $\mathrm{I}_{2}$ deposited on the epoxy-paint sample during the loading phase are in the order of $(5.5 \pm 0.2) 10^{-4} \mathrm{~mol} \mathrm{~m}^{-2}$.

\subsection{Gamma irradiation}

All studied materials were irradiated by gamma rays from ${ }^{60} \mathrm{Co}$ radiation. The irradiation steps were carried out in two different places, depending on the dose to reach: ( $300 \mathrm{kG}$ y and $1000 \mathrm{kG}$.). Irradiation steps were performed under air at around $60{ }^{\circ} \mathrm{C}$ with a dose rate of $2.5 \mathrm{kGy} \mathrm{h}^{-1}$, and at around $40{ }^{\circ} \mathrm{C}$ with a dose rate of $6,0 \mathrm{kGy} \mathrm{h}^{-1}$ in the second case. The extent of chemical changes produced by irradiation depends on the amount of energy absorbed by the system. The absorbed dose is expressed in Gray (Gy) which corresponds to an absorbed energy of $1 \mathrm{~J} / \mathrm{kg}$ of matter. "Dosimeters" were used to measure the irradiation dose rate allowing to calculate the absorbed dose of the studied samples, depending on their irradiation time. Dosimetry was performed using the alanine method [26] or Perspex films [27] (routine measurements).

After gamma irradiation, samples were stored in an airconditioned room at $21{ }^{\circ} \mathrm{C}$ in plastic bags shielded from UV rays in order to avoid further potential post-gamma radiation degradation.

\subsection{MIR-ATR characterization}

Mid Infrared spectroscopy measurements were carried out on a thin film in the ATR (Attenuated Total Reflectance) mode on a Thermo Scientific Nicolet iN10 MX Infrared Imaging Microscope. This apparatus is equipped with a microscope allowing micro-FTIR measurements. Samples were placed without preparation on the stage of FTIR imaging system and were analyzed using a liquid nitrogen-cooled Mercury Cadmium Tellurite (MCT) detector. The 


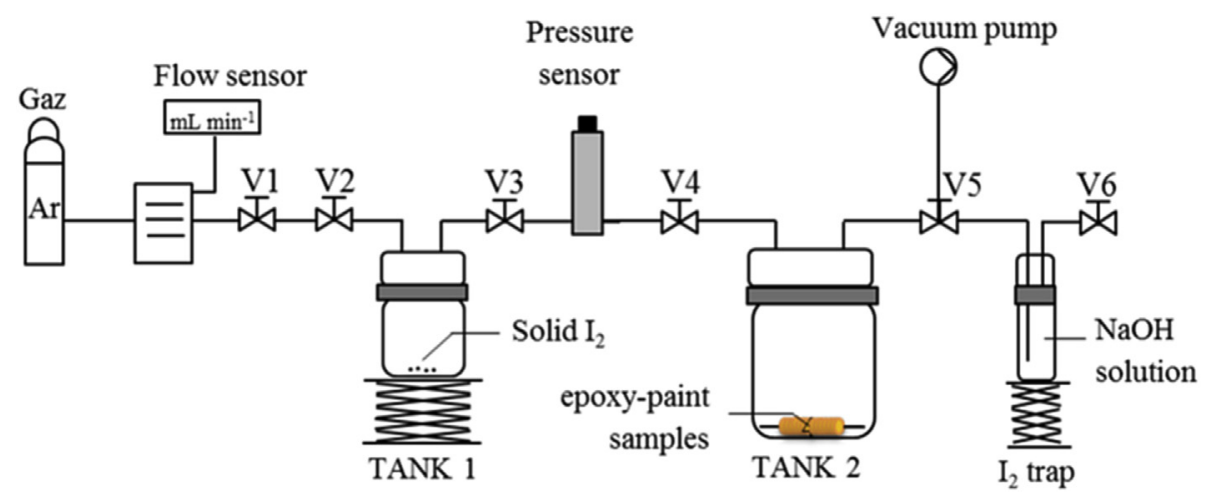

Fig. 1. Device used to load the epoxy-paint samples with gaseous $I_{2}$.

mapping area had a size of $160 \mu \mathrm{m} \times 160 \mu \mathrm{m}$, and the images were acquired with a pixel size of $20 \mu \mathrm{m}$ with $4 \mathrm{~cm}^{-1}$ resolution and 64 scans in the wave number range of $4000-675 \mathrm{~cm}^{-1}$, indicating that 64 spectra $(8 \times 8)$ were involved in an ATR/FTIR image. The MIR spectrometer was situated in an air-conditioned room $\left(21^{\circ} \mathrm{C}\right)$ and air was taken as reference for the background spectrum before each map. Between maps, the ATR accessory was cleaned with ethanol solution, enabling to dry the ATR. Cleanliness was verified by collecting a background spectrum and comparing to the previous background spectrum. The analyzed depth is wavelength dependent and is between 0.5 and $3 \mu \mathrm{m}$.

\subsection{AComDim}

To determine the impact of the different factors on sample measurements, signal intensity variations (due to each factor and interaction) were compared to other sources of variations, either "noise" or uncontrolled factors of influence. The AComDim [22,28-30] method was used in this study to check if spectral variations due to a change of factor level are greater than residual variability (noise or experimental error). AComDim is proposed here as a multivariate technique to analyse experimental designs. It is able to highlight the influential factors and their interactions as defined by the experimental design. AComDim is based on the same concept as ANOVA-PCA [31] (also called APCA). The experimental data matrix is decomposed into successive matrices containing the mean at each level for each factor or interaction. The residuals matrix obtained after the successive subtractions of all the mean matrices is then added back to each matrix of means. In a second step of APCA, a PCA is applied to each matrix of means plus residuals. Groups formed by samples in the $\mathrm{PC} 1-\mathrm{PC} 2$ plane are examined in order to evaluate the significance level of each factor compared to the residuals. With AComDim, the separate PCAs of the second step are replaced by a single simultaneous analysis of all matrices with ComDim, a multi-block analysis method. From a mathematical point of view, AComDim determines a common space for the $p$ data matrices $X_{i}$, each with $n$ sample rows. Each matrix $X_{i}$ is column-centered and normalized to obtain the scaled matrix $X_{i s}$. For each $X_{i s}$ the matrix $X_{i s} . X_{i s}^{T}$ is computed to obtain the samples variance/covariance matrix $W_{i}$ which represents the sample dispersion in the space of the variables of that table. The main idea of ComDim [28] is first to calculate $W_{\mathrm{G}}$, a weighted sum of the sample variance/covariance matrix $X_{i s} X_{i s}^{\mathrm{T}}$, for each table, $X_{i s}$, and then to extract its first Principal Component, or Common Component (CC). For each successive common dimension, the scores vector $q$ (coordinates of the $n$ samples along the common dimension) are calculated by the equation:
$W i=\sum_{j=1}^{j=n} \lambda_{j}^{(i)} q_{j} q_{j}^{t}$

with $\lambda_{j}^{(i)}$ specific weight ("salience") related to the $i^{\text {th }}$ table for the common dimension $j$ produced by $q_{j}$.

Each matrix $W_{i}$ provides a specific contribution ("salience") to the definition of each dimension of this common space. The salience $\lambda_{i}$ of each table on the CCs is determined iteratively.

$\lambda_{i}(1)=q_{1}^{T} W_{i} q_{1}$

The computed saliences indicate which Common Components contribute most to each table. In the case of AComDim, the saliences indicates which factor or interaction contributes most to each CC. The first Common Component CC1 is should correspond to the effect of the residuals since as they are added back to each factor matrix all blocks contain a contribution from the residual error matrix. The blocks that contribute significantly to CC1, i.e. with high saliences are those that contain little variance other than that due to the residuals. Less a block contributes to $\mathrm{CC} 1$, the more its source of variability is different from the residuals. To estimate the significance of a block, one can apply an Fisher test [32]. The saliences can be considered as measures of variances so the F-test of a block can be computed as the ratio between the salience of the residual block on CC1 and the salience of that block on CC1. The F-test is performed by selecting $n-1^{\circ}$ of freedom for both variances.

$F_{i}=\frac{\lambda_{\text {res }}}{\lambda_{i}}=\frac{q_{1}^{T} W_{\text {res }} q_{1}}{q_{1}^{T} W_{i} q_{1}}$

where $\lambda_{\text {res }}$ is the salience of the residual block on CC1 and $\lambda_{i}$ is the salience of the $i$ th block on CC1.

The alpha level is set equal to 0.05 to be statistically significant. The blocks for which the ratio is greater than the critical value of the Fisher table [33] are considered as being related to influential factors or interactions. The probability value ( $p$-value) is also calculated for each F-test, it represents the probability that the variability is due only to noise. The more this value is close to zero and more the block is associated with a significant factor. All computations were performed using Matlab 7.14 (R2012a). The AComDim procedure was adapted from the ComDim function in the free toolbox SAISIR [30].

\subsection{Experimental design}

The spectra were used as responses to full-factorial experimental design built taking into account the different levels of the 
factors, as summarized in Table 1 . The full-factorial design investigated one two-level factors for "Iodine content" one three-level factor (for "gamma dose") and included $2 * 3=6$ experiments (excluding center points). These full-factorial designs were perfectly balanced, i.e., the number of experiments was the same for all the levels of a factor.

\section{Results and discussion}

The interpretation of AComDim infrared spectra requires as a first step the assignment of the characteristic vibrational bands initially present in the epoxy-paint. In the following discussion, the spectral data of each component of the epoxy-paint (DGEBA and PAA) will be first interpreted separately. Then in order to study the influence of the parameters: the irradiation dose and presence of iodine loaded on the epoxy-paint, all spectral data were analyzed using AComDim approach.

\subsection{Initial MIR-ATR characterization}

The FTIR spectra of the different DGEBA and PAA, which are the two component of the epoxy-paint, are well described in the literature [34-42]. The infrared assignments of the two structures are detailed in Table 2 .

The epoxy-paint is obtained by mixing at room temperature DGEBA and PAA components. The FTIR spectrum of epoxy-paint is given in Fig. 2. The assignment of the infrared characteristic vibrational bands, and their link with the initial components of the paint (DGEBA or PAA) are detailed in Table 3. The mixture of the DGEBA and PAA components leads to a tridimensional network structure by reaction between the epoxy cycle of the DGEBA components and the amine adduct of the PAA (Fig. 3). The FTIR spectrum of epoxy-paint indeed shows the disappearance of the band at $915 \mathrm{~cm}^{-1}$ characteristic of the deformation of the epoxy cycle and the appearance of a band at $1010 \mathrm{~cm}^{-1}$ characteristic of the elongation of $\mathrm{C}-\mathrm{OH}$ bond due to the formation of alcohol function by opening of the epoxy cycle. It can be also noted the presence of a small band at $1734 \mathrm{~cm}^{-1}$ characteristics of the presence of carbonyl products formed certainly by photooxidation $[43,44]$ under ambient light during the $24 \mathrm{~h}$ drying of the paint (see $\S 2.2$ ).

The characteristic bands of the epoxy-paint being located between 1800 and $800 \mathrm{~cm}^{-1}$, the AComDim studies are limited to this range of wave numbers.

\subsection{Significant factors}

AComDim, gives quantitative information about the variability of the spectroscopic data resulting from the effect of the integrated dose or iodine loading. The extracted Common Components (CCs), obtained with AComDim treatment, indicate whether variations in the data between levels of a factor are significantly greater than the residual variability. The less a block contributes to CC1 (residuals), the more its source of variability is different from the residuals. The

Table 1

Level of factor for each experiment.

\begin{tabular}{ll}
\hline iodine & dose \\
\hline Yes & 300 \\
Yes & 0 \\
Yes & 1000 \\
No & 0 \\
No & 1000 \\
No & 300 \\
\hline
\end{tabular}

AComDim analysis gives the salience values of these blocks on each CC (Common Component), which are all the observations varying at the same time of the factors studied (e.g. integrated dose). The saliences allow finding the significant factors. The F-values are computed from the saliences on $\mathrm{CC} 1$ as the ratio between the salience of the residual block (i.e. block 4) and the salience of each other block (i.e. block 1-3). As presented on Fig. 4(a), the blocks 1 (integrated dose, 7\% of total variability), 2 (iodine loading, 5\% of total variability) and 3 (interaction dose-iodine, $4 \%$ of total variability) have higher F-values (respectively 4.06, 1.33, 1.35) compared to the critical value $(\mathrm{Fc}=1.18)$ of the Fisher table $\left(\alpha=0.05,383^{\circ}\right.$ of freedom).

\subsection{Degradation of epoxy-paint samples by gamma radiation}

The modifications of epoxy-paint (loaded with $\mathrm{I}_{2}$ or not) structure under gamma radiations under air atmosphere were studied by comparison of the MIR-ATR spectra of non-irradiated and irradiated (300 kG y and 1 MGy) epoxy-paint samples. There is no significant difference between the spectra of non-irradiated and irradiated epoxy-paint samples observable with the naked eye, even for the strongest integrated dose (1 MGy) except regarding some band intensities (see Supporting information Fig. 9).

This is in good agreement with the low percentage of total variability (7\%) associated to gamma irradiation. Indeed on these raw spectra, no FTIR band due to the formation of radiolysis products (carbonyl, alcohol compounds, double bonds...) is directly highlighted. In order to assess the modifications of the structure of epoxy-paint, an AComDim analysis has been performed (Fig. 5).

The score projection associated to the CC3 shows good discrimination of samples according to the integrated dose. Samples irradiated are projected to the right in Fig. 5 far from the nonirradiated sample.

The irradiated samples are characterized by absorption bands pointed at 1218, 1280, 1330-1380, 1631, 1658 and $1712 \mathrm{~cm}^{-1}$. These bands are not initially present in spectral data of the epoxy-paint, they correspond to radio-induced modifications of the epoxypaint structure leading to the formation of radiolysis products such as of carbonyl compounds, amides, double bonds $[37,38,45-47]$. Indeed the bands at 1218 and $1280 \mathrm{~cm}^{-1}$ can be attributed to $v(\mathrm{C}-\mathrm{O})$ of carboxylic acids radiooxidative products. The band at $1712 \mathrm{~cm}^{-1}$ is characteristic of the $v(C=0)$ of carboxylic acids. The bands at 1658 and $1631 \mathrm{~cm}^{-1}$ are attributed to amide radiooxidative products $(v(\mathrm{C}=\mathrm{O})$ and $\delta(\mathrm{N}-\mathrm{H})$ respectively). This last band at $1631 \mathrm{~cm}^{-1}$ can be also attributed to the formation of double bonds. The broad band between 1330 and $1380 \mathrm{~cm}^{-1}$ may be attributed to $\delta(-\mathrm{OH})$ of carboxylic acids but also to $v(\mathrm{C}-\mathrm{N})$ of the amides functions.

The non-irradiated samples are characterized by absorption bands pointed at 821 and $1565 \mathrm{~cm}^{-1}$. These bands are initially present with a little shift in the spectral data of the epoxy-paint, the shift being linked to the formation of the carbonyl and amide compounds previously highlighted.

The carbonyl compounds radio-induced are mainly carboxylic acids as chains end-groups [21]. The formation of carboxylic acids can result from various pathways by oxidation of the polyamidoamine segments or by oxidation of the i-propanol unit. The formation of these carbonyl functions in $\alpha$ or $\beta$ of the aromatic cycle (highlighted in green on Fig. 6) may change the frequency values of the bonds of the cycle. That is why the $\gamma(\mathrm{C}-\mathrm{H})$ of aromatic cycle initially located at $827 \mathrm{~cm}^{-1}$ is shifted to $821 \mathrm{~cm}^{-1}$ and is revealed by the AComDim. The formation of amides occurs by the oxidation of amino methylene in the vicinity of networks node [21] leading to the formation of a tertiary amide (highlighted in orange on Fig. 6). The formation of these amides may change the frequency values of 
Table 2

Infrared assignments of the DGEBA and PAA.

\begin{tabular}{|c|c|c|c|}
\hline Wavenumbers $\left(\mathrm{cm}^{-1}\right)$ & Assignment & Wavenumbers $\left(\mathrm{cm}^{-1}\right)$ & Assignment \\
\hline DGEBA & & PAA & \\
\hline 3055 & $v_{\text {as }}(\mathrm{C}-\mathrm{H})$ epoxy cycle & 3273 & $v(\mathrm{~N}-\mathrm{H})$ amine or amide units \\
\hline 2965 & $v_{\mathrm{as}}(\mathrm{C}-\mathrm{H}) \mathrm{CH}_{3}$ units & 2920, 2851 & $v(\mathrm{C}-\mathrm{H}) \mathrm{CH}_{2}$ units \\
\hline 2925 & $v(\mathrm{C}-\mathrm{H}) \mathrm{CH}_{2}$ units & 1640 & $v(\mathrm{C}=\mathrm{O})$ amide units \\
\hline 2871 & $v_{\mathrm{s}}(\mathrm{C}-\mathrm{H}) \mathrm{CH}_{2}$ units & 1555 & $\delta(\mathrm{N}-\mathrm{H})$ amine or amide units \\
\hline $1606,1582,1507$ & $v(\mathrm{C}=\mathrm{C})$ aromatic cycle & 1461 & $\delta(\mathrm{C}-\mathrm{H}) \mathrm{CH}_{2}$ units \\
\hline 1453 & $\delta(\mathrm{C}-\mathrm{H}) \mathrm{CH}_{2}$ epoxy cycle & 1248,1181 & $v(\mathrm{C}-\mathrm{N})$ amine or amide units \\
\hline 1384,1362 & $v(\mathrm{C}-\mathrm{C}) \mathrm{C}-\mathrm{Me}_{2}$ units & & \\
\hline $1296,1238,1182$ & $v_{s}(\mathrm{C}-\mathrm{O})$ phenolic ether & & \\
\hline 1107,1035 & $v_{s}(C-O)$ aliphatlic ether & & \\
\hline 970 & $\delta(\mathrm{C}-\mathrm{O})$ aliphatlic & & \\
\hline 914 & $\checkmark$ epoxy cycle & & \\
\hline 829 & $\gamma(\mathrm{C}-\mathrm{H})$ aromatic cycle & & \\
\hline
\end{tabular}

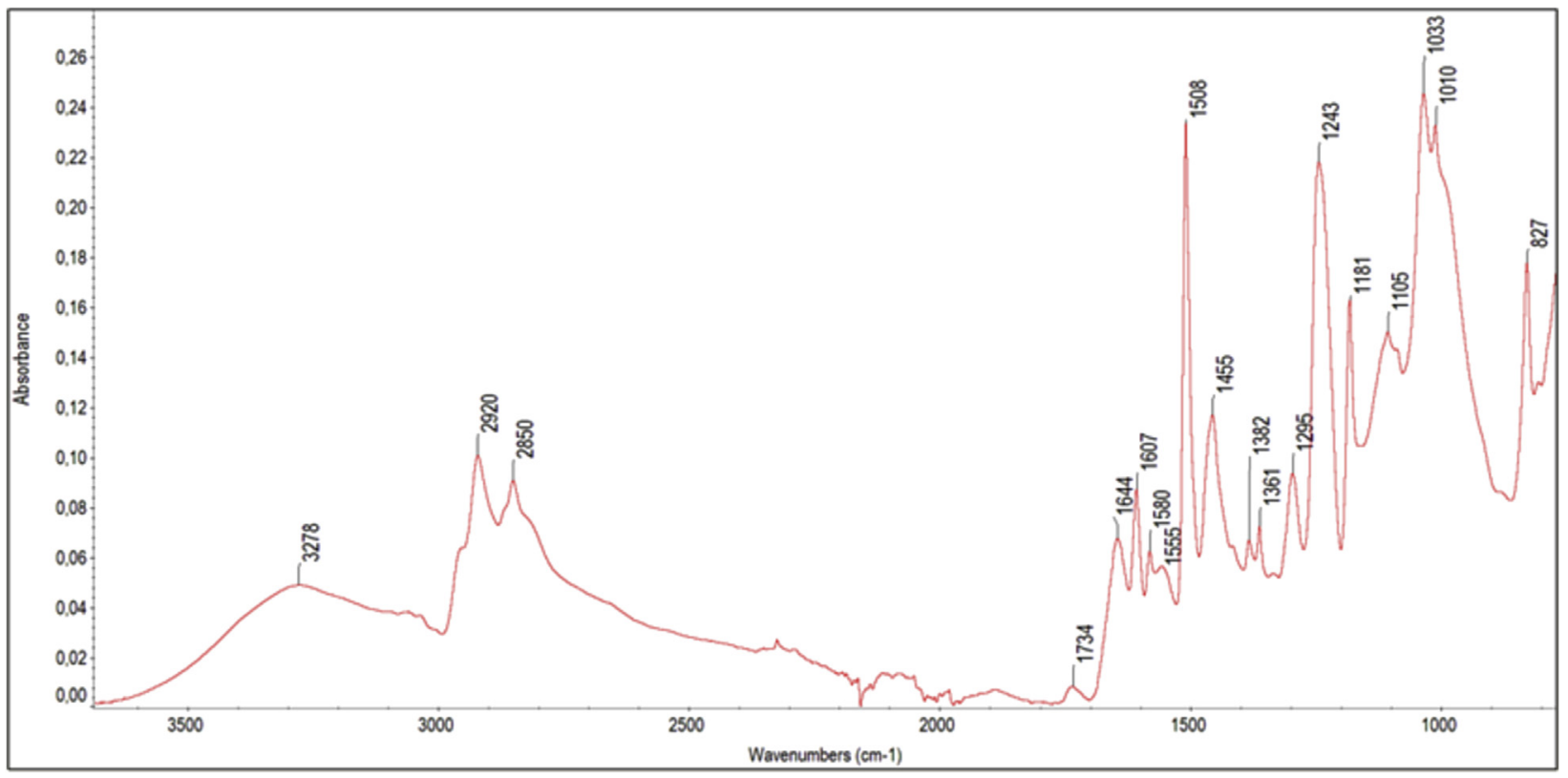

Fig. 2. Epoxy-paint MIR-ATR spectrum.

the bonds in the vicinity, particularly of the secondary amine. That is why the $\delta(\mathrm{N}-\mathrm{H})$ of initially located at $1555 \mathrm{~cm}^{-1}$ is shifted to $1565 \mathrm{~cm}^{-1}$ and is revealed by the AComDim. The formation of double bonds (highlighted in blue on Fig. 6) occurs in the amine linkage [40].

It should be noted that the scores of the samples are not classified according to the value of the integrated dose (the highest dose has not the largest score value). These results may be linked to the difference of the irradiation conditions for the 2 doses studied (obtained in two facilities, see $\S 2.3$ ): $60{ }^{\circ} \mathrm{C}, 2.5 \mathrm{kGy} \mathrm{h}^{-1}$ to reach a $300 \mathrm{kGy}$ dose and $40^{\circ} \mathrm{C}, 6 \mathrm{kGy} \mathrm{h}^{-1}$ to reach a $1000 \mathrm{kGy}$ dose. Such a temperature deviation cannot lead to changes in radiolysis mechanisms. On the other hand, it is well known that the oxidative radiolysis mechanisms are influenced by the dose rate [48-50]. So, the samples irradiated at $300 \mathrm{kG}$ y are subjected to lower dose rate and to higher temperature and in these conditions the $\mathrm{O}_{2}$ diffusion in the material is favoured, compared to the samples irradiated at $1000 \mathrm{kG}$. For the samples irradiated at $300 \mathrm{kGy}$, the formation of oxidative radiolysis products is favoured, whereas for the samples irradiated at $1000 \mathrm{kGy}$ more mechanisms not involving oxygen occur (crosslinking, double bond formation [40]) which may explain the position of the score regarding the dose on the
AComDim.

\subsection{Modification of MIR spectra after loading of epoxy-paint samples with $\mathrm{I}_{2}$}

The modifications of the spectra of epoxy-paint samples after the loading phase with $\mathrm{I}_{2}$ were studied by comparison of the MIRATR spectra of the $I_{2}$ loaded and unloaded epoxy-paint samples. There is no significant difference between the spectra of the loaded and unloaded epoxy-paint samples, even for the strongest concentration of $\mathrm{I}_{2}\left(10^{-3} \mathrm{~mol}\left(\mathrm{I}_{2}\right) / \mathrm{m}^{2}\right)$ (see Supporting information Fig. 10). This is in good agreement with the low percentage of total variability (5\%) associated to iodine content. Indeed on these raw spectra, no FTIR band due to the formation of bond or interaction between Iodine ant the epoxy-paint structure is directly highlighted. In order to assess the modifications of the spectra of epoxy-paint samples after having loaded with $\mathrm{I}_{2}$ and to possibly identify the nature of the iodine-paint interactions, an AComDim analysis has been performed (Fig. 7).

The score projection associated to the CC2 (Fig. 7(a)) shows good discrimination of samples according to the loading of epoxy-paint samples with $\mathrm{I}_{2}$, and thus probably according to interactions 


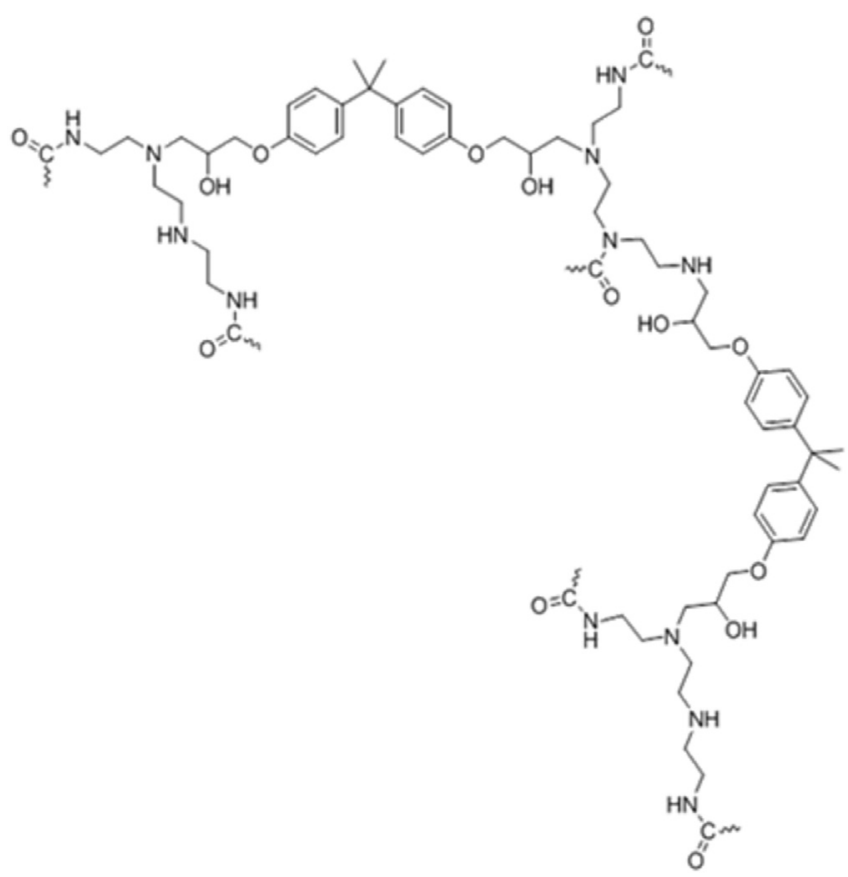

Fig. 3. Epoxy-paint (DGEBA/PAA) structure. epoxy-paint and associated to the $v_{s}(\mathrm{C}-\mathrm{OH})$ created by the opening of the epoxy cycle during the reaction between DGEBA and PAA (see Table 2). The band at $1592 \mathrm{~cm}^{-1}$ may be linked to a shift of the band at $1580 \mathrm{~cm}^{-1}$ initially present in the spectra data of the epoxypaint and associated to the $v(\mathrm{C}=\mathrm{C})$ of the aromatic cycle of the epoxy-paint structure. The band at 1550 and $1650 \mathrm{~cm}^{-1}$ may be linked to shifts of the band at 1555 and $1640 \mathrm{~cm}^{-1}$ initially present in the spectra data of the epoxy-paint and associated respectively to $\delta(\mathrm{N}-\mathrm{H})$ of the amine and/or amide and $v(\mathrm{C}=\mathrm{O})$ of the amide functions of the epoxy-paint structure.

These previous bands highlighted on Fig. 7(b) are associated with bonds of the epoxy-paint structures affected by the interactions of epoxy samples with $\mathrm{I}_{2}$. The literature on $\mathrm{I}_{2}$ reaction with epoxy-paint and more generally with polymer is scarce. Two kinds of reactions can be considered according to the literature: $\mathrm{CI}$ bond formation or formation of a charge-transfer complexe, as explained below.

On the one hand, some studies based on theoretical ab initio calculations in order to identify the most likely reactions pathways and the most stable compounds formed from $\mathrm{I}_{2}$ and epoxy paint were performed at $373 \mathrm{~K}$ [51]. These results showed that the reaction of $\mathrm{I}_{2}$ on the polymer would mainly take place on aminoalcohol functions and more precisely on the carbon located between amine and alcohol groups. The free energy change $(\Delta \mathrm{G})$ calculated on this site to create the $\mathrm{C}-\mathrm{I}$ bond is between -10

Table 3

Infrared assignments of epoxy paint.

\begin{tabular}{lll}
\hline Wavenumbers $\left(\mathrm{cm}^{-1}\right)$ & Assignment & Component attribution \\
\hline 3278 & $v(\mathrm{~N}-\mathrm{H})$ & PAA \\
2920,2850 & $v(\mathrm{C}-\mathrm{H}) \mathrm{CH}_{2}$ units & DGEBA and PAA \\
1734 & $v(\mathrm{C}=\mathrm{O})$ carbonyl products & Oxidative degradation products of the paint \\
1644 & $v(\mathrm{C}=\mathrm{O})$ amide units & PAA \\
$1607,1580,1508$ & $v(\mathrm{C}=\mathrm{C})$ aromatic cycle & DGEBA \\
1555 & $\delta(\mathrm{N}-\mathrm{H})$ & PAA \\
1455 & $\delta(\mathrm{C}-\mathrm{H}) \mathrm{CH}_{2}$ units & DGEBA and PAA \\
1382,1361 & $v(\mathrm{C}-\mathrm{C}) \mathrm{C}-\mathrm{Me}_{2}$ units & DGEBA \\
$1295,1243,1181$ & $v_{\mathrm{s}}(\mathrm{C}-\mathrm{O})$ phenolic ether and $v(\mathrm{C}-\mathrm{N})$ & DGEBA and PAA \\
1105,1033 & $v_{\mathrm{s}}(\mathrm{C}-\mathrm{O})$ aliphatic ether & DGEBA \\
1010 & $v_{\mathrm{s}}(\mathrm{C}-\mathrm{OH})$ & Created by the opening of the epoxy cycle \\
827 & $\gamma(\mathrm{C}-\mathrm{H})$ aromatic cycle & DGEBA \\
\hline
\end{tabular}

between iodine and epoxy-paint. On the Principal Component CC2 (Fig. 7(b)), the MIR vibrational bands in positive part differentiate the epoxy-paint samples loaded with $\mathrm{I}_{2}$ from those unloaded.

The epoxy-paint samples unloaded with $\mathrm{I}_{2}$ are characterized by absorption bands pointed at 829, 1184, 1241 and $1508 \mathrm{~cm}^{-1}$. These bands are initially present, with a little shift, in spectral data of the epoxy-paint. The bands pointed at $1241 \mathrm{~cm}^{-1}$ and $1184 \mathrm{~cm}^{-1}$ are associated to the shift of the bands relative to $v(\mathrm{C}-\mathrm{N})$ of amine and/ or amide units of the epoxy-paint structure, initially present at 1248 and $1181 \mathrm{~cm}^{-1}$ respectively. The two other bands at 829 and $1508 \mathrm{~cm}^{-1}$ are associated to the $\gamma(\mathrm{C}-\mathrm{H})$ and $v(\mathrm{C}=\mathrm{C})$ of the aromatic cycle of the epoxy-paint structure. These bands present in the negative part of Fig. 7(b) shows that the associated functions (amine and/or amide and aromatic cycle) are involved in the interactions between iodine and epoxy-paint.

The epoxy-paint samples loaded with $\mathrm{I}_{2}$ are characterized by absorption bands pointed at 995, 1550, 1592 and $1650 \mathrm{~cm}^{-1}$. These bands are not initially present in spectral data of the epoxy-paint, but they may correspond to shift of bands initially present linked to a modification due to the loading with $\mathrm{I}_{2}$ of parts of the epoxypaint structure. The band at $995 \mathrm{~cm}^{-1}$ may be linked to a shift of the band at $1010 \mathrm{~cm}^{-1}$ initially present in the spectra data of the and $-15 \mathrm{~kJ} \mathrm{~mol}^{-1}$ at $373 \mathrm{~K}$. Similar calculations show that at ambient temperature, i.e. in the experimental conditions, this value of $\Delta \mathrm{G}$ remains unchanged, this reaction would be therefore thermodynamically expected at ambient temperature.

On the other hand, other studies report a mechanism involving charge transfer interactions of iodine as a $\sigma$-acceptor with electron donors parts of the epoxy structure. The charge-transfer complexes formed between iodine and several types of electron donor have been largely studied [52-56]. Amines are particularly appropriate candidates to form charge-transfer complexes due to the mobility of the nonbonding doublet of nitrogen giving electron donor properties. Aromatic molecules are also known to have electron donors properties and thus to form charge-transfer complexes with iodine. The most suitable technique to highlight a charge-transfer complex is UV spectroscopy, but in the case of the present study this technique is unsuccessful due to the presence of additives $\left(\mathrm{TiO}_{2}\right)$ in small amount saturating the spectrum in the spectral range of interest. The MIR spectra of charge-transfer complexes show usually a shift, a broadening or a change of intensity of the bands characteristic of the part or of the function of the initial molecule involved in the interaction donor-acceptor with Iodine [57-59]. 


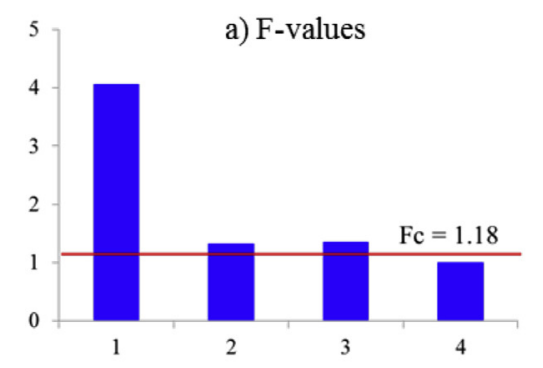

b) Saliences
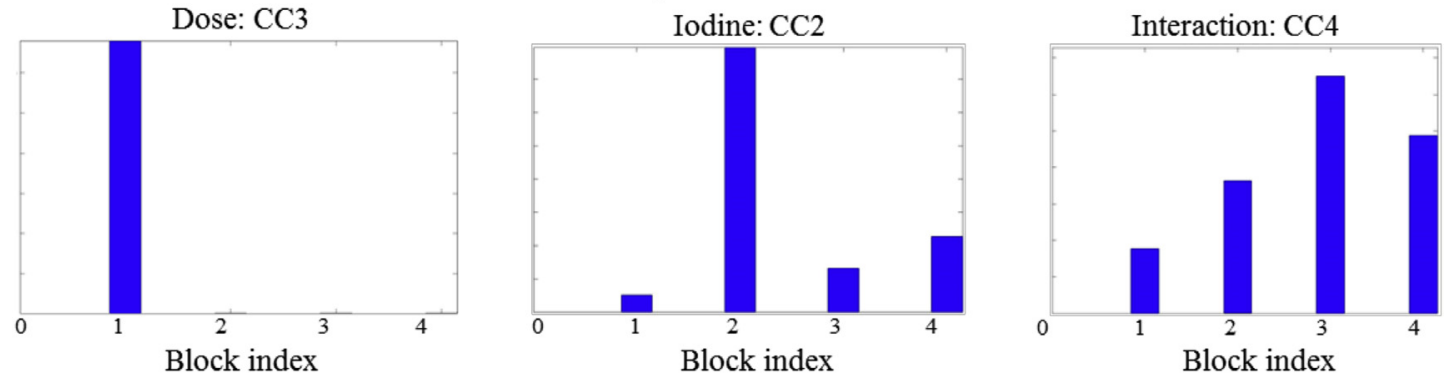

Fig. 4. AComDim applied on Epoxy-paint MIR-ATR data: (a) F-values and (b) saliences.

a) Scores on CC3 (vs CC1) for the factor " Dose"

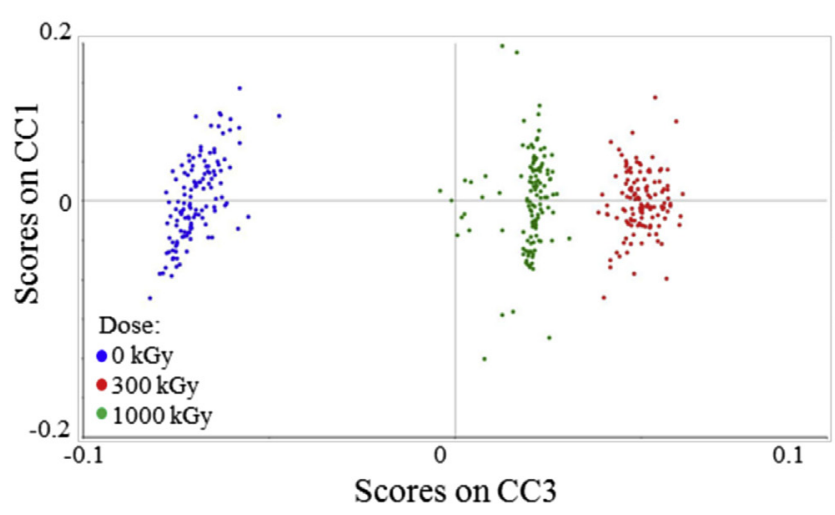

b) Loading plot on CC3 for the factor « Dose "

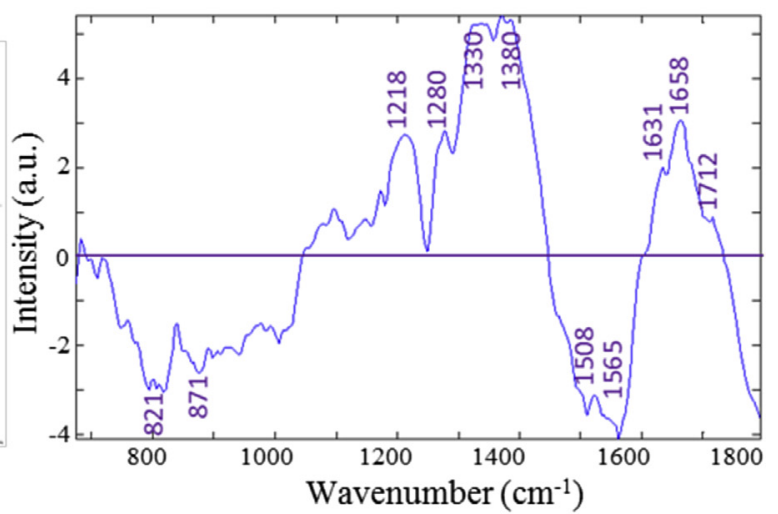

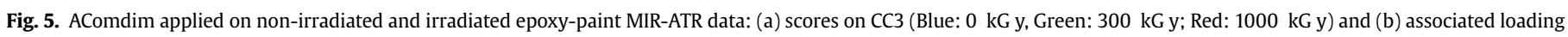
plot. (For interpretation of the references to colour in this figure legend, the reader is referred to the web version of this article.)<smiles>CC(=O)NC=CN(CCN(CCNCC(O)CO)C(C)=O)CC(O)COc1ccc(C(C)(C)c2ccc(OCC(O)=CN(C=CN(CCNC(C)=O)C(C)=O)CCNC(C)=O)cc2)cc1</smiles>

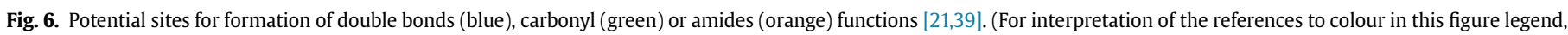
the reader is referred to the web version of this article.) 
a) Scores on $\mathrm{CC} 2$ (vs CC1) for the factor « Iodine"

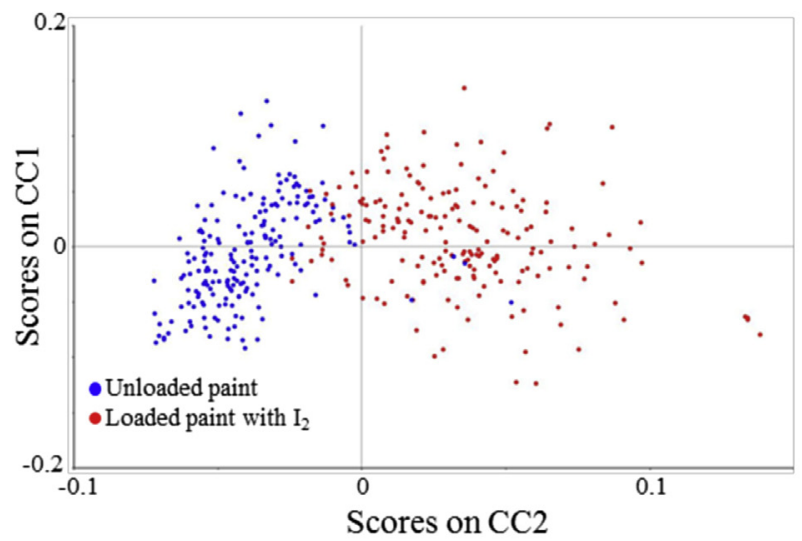

b) Loading plot on $\mathrm{CC} 2$ for the factor « Iodine»

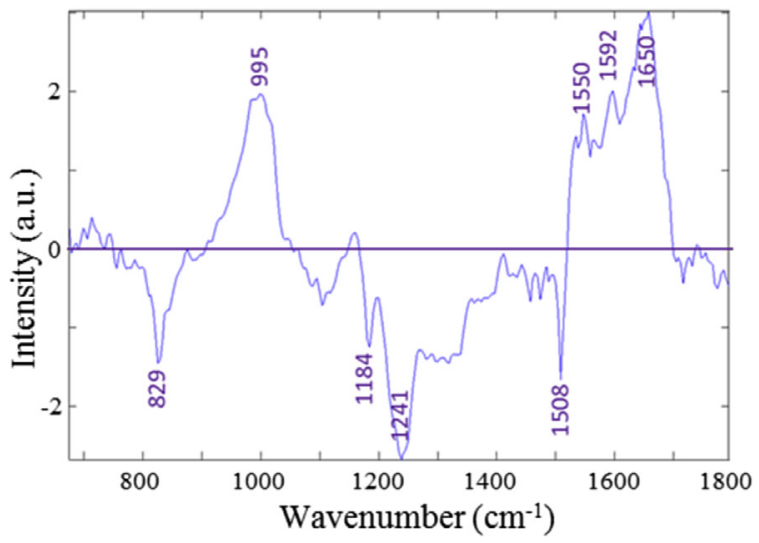

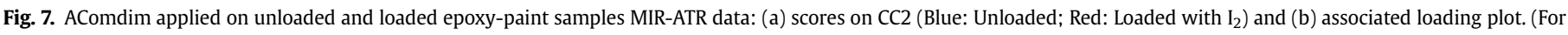
interpretation of the references to colour in this figure legend, the reader is referred to the web version of this article.)

In the case of the present study, the presence of the $\mathrm{C}-\mathrm{I}$ bond has not been highlighted as no band was observed in the FTIR spectra range of interest (the characteristic band of the $\mathrm{C}-\mathrm{I}$ bond is located between 480 and $660 \mathrm{~cm}^{-1}$ ) even after the loading of epoxy-paint samples with $\mathrm{I}_{2}$. Otherwise, this study seems to confirm the existence of a charge-transfer complex as we can observe that the bands highlighted by Fig. 4(b) and thus involved in the interactions of epoxy samples with $\mathrm{I}_{2}$ are associated with the electron donors parts of the epoxy structure i.e. with the amine and/or amide functions $(v(\mathrm{C}-\mathrm{N})$ for the bands at 1241 and $1184 \mathrm{~cm}^{-1}, \delta(\mathrm{N}-\mathrm{H})$ for the band at $1550 \mathrm{~cm}^{-1}$ and $v(\mathrm{C}=\mathrm{O})$ for the band at $\left.1650 \mathrm{~cm}^{-1}\right)$ and to the aromatic cycle: $\gamma(\mathrm{C}-\mathrm{H})$ for the band at $829 \mathrm{~cm}^{-1}, v(\mathrm{C}=\mathrm{C})$ for the bands at 1508 and $1592 \mathrm{~cm}^{-1}$. The band at $995 \mathrm{~cm}^{-1}$ associated to the $v_{\mathrm{s}}(\mathrm{C}-\mathrm{OH})$ highlighted in Fig. 4(b) may be due to the formation or the modification of an hydrogen bond of the alcohol function in the charge-transfer complex.

\subsection{Interaction "dose - iodine"}

The score projection associated to the CC4 (Fig. 8) shows discrimination of samples according to interactions between the factors "Dose" and "Iodine". The profile of Fig. 8(a) is related to the score projection associated to the CC2 (Fig. 7(a)) showing discrimination of samples according to the loading of epoxy-paint samples with $\mathrm{I}_{2}$ : the two profiles are the inverse of one another, and the bands highlighted on Figs. 7(b) and 8(b) are the same. These similarities reveal a dependency of the amount of iodine present on the epoxy-paint according to the integrated dose. This is in good agreement with the low percentage of total variability (4\%) associated to iodine and gamma irradiation interaction. These results are consistent with the studies performed on the volatization of iodine loaded on the paint under radiation [60,61]. Indeed several studies showed that under radiation the iodine initially loaded on the epoxy-paint is volatized under several forms $\left(I_{2}(g)\right.$, $\mathrm{RI}(\mathrm{g})$ and aerosols) and this volatilization increases with the integrated dose. So the amount of iodine volatilized from a paint sample loaded with $\mathrm{I}_{2}$ and irradiated at $1000 \mathrm{kGy}$ is higher than the amount of iodine volatilized from a sample irradiated at $300 \mathrm{kGy}$. This in turn indicates that the amount of iodine remaining on the paint sample is lower at $1000 \mathrm{kGy}$ than at $300 \mathrm{kGy}$ and highlights the dependency of the amount of iodine present on the epoxy-paint according to the integrated dose and thus the interactions of the factors "Dose" and "Iodine" revealed by the AComDim.

\section{Conclusion}

In case of a severe accident on a NPP, fission products can be released from the nuclear fuel to the reactor containment building. Among them, volatile iodine $\left(\mathrm{I}_{2}\right)$ can be produced and can interact with the epoxy-paint (DGEBA/PAA paint, representative of the paint that covers the inner surfaces of the French nuclear reactor containment buildings). This work aimed to characterize the iodine-paint interactions, to identify the radiation damages on the epoxy-paint, and to check their effects on these iodine-paint interactions. This work shows the potential of multi-block analysis method (ANOVA-PCA and COMDIM = AComDim) for such a study as it allows to identify the nature of iodine/epoxy-paint interactions and to highlight the differences caused by several paint ageing processes and to characterize the gamma radiation damages on the epoxy-paint. AComDim method conduces to the extraction of Common Components to different tables and highlights factors of influence and their interactions.

The influential factors, as gamma integrated dose and iodine loading, on epoxy-paint samples after gamma irradiation at different integrated doses $(0,300,1000 \mathrm{kGy})$ were studied. The AComDim method showed the most significant factors involved and the different potential interactions. The AComDim method reveals that gamma irradiation induces modifications on epoxypaint samples: the appearance of characteristic FTIR bands or the shift of other ones highlight the formation of oxidative radiolysis products. A thorough study of these FTIR bands shows that they are due to carboxylic acids, amides and double bonds functions produced by radiolysis of epoxy-paint. These modifications are attributed to gamma irradiation dose even if there is a confounding effect of gamma irradiation and temperature. The AComDim method reveals also the interaction nature between epoxy-paint and iodine: the shifts, broadenings or changes of intensity of the characteristic bands of the different electron donor parts of the epoxy-paint highlight that charge-transfer complexes are formed between iodine and epoxy-paint. The study of these FTIR bands shows that the amine and/or amide functions and aromatic cycle parts of the epoxy-paint structure are involved in the interaction donor-acceptor with iodine. At last, the volatization of iodine initially loaded on the epoxy-paint sample is highlighted by the AComDim factors Interactions study showing the dependency of the amount of iodine present on the epoxy-paint according to the integrated dose.

This works will be helpful to better understand the iodine-paint 

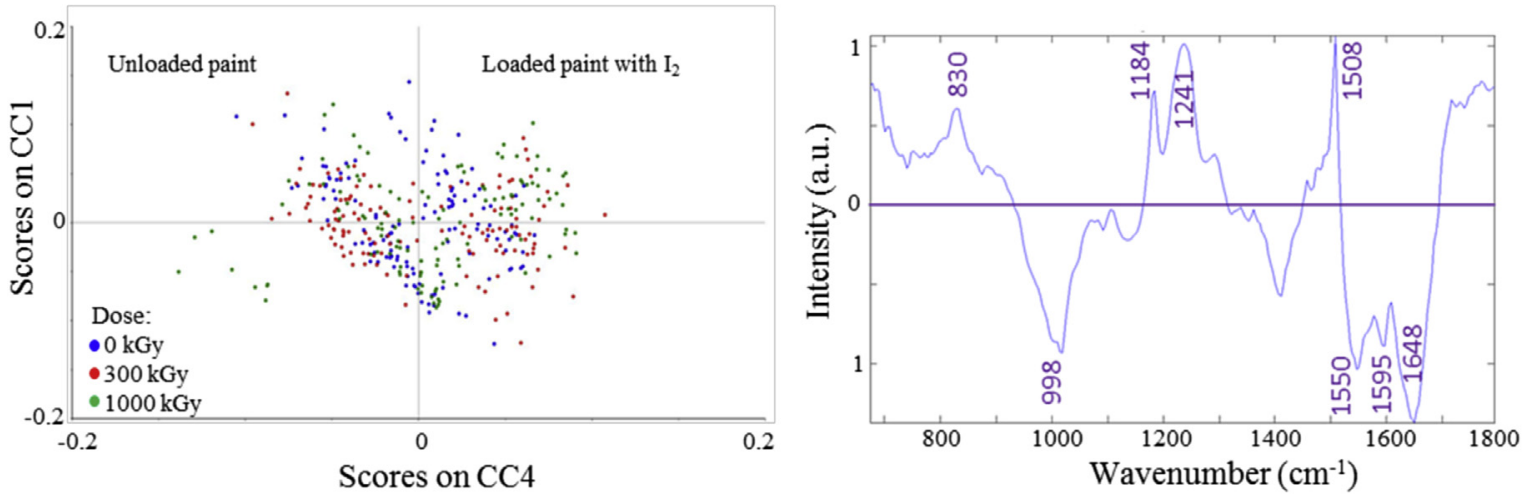

Fig. 8. AComdim applied on Interaction integrated dose" and "Iodine loading MIR-ATR data: (a) scores on CC4 and (b) associated loading plot.

interaction behaviour and the conditions of radioactive iodine release to the environment in case of a nuclear severe accident.

\section{Acknowledgments}

The authors wish to acknowledge Loïc Bosland from IRSN for ab initio calculations and for scientific exchanges.

\section{References}

[1] M. Schwarz, G. Hache, P. von der Hardt, PHEBUS FP: a severe accident research programme for current and advanced light water reactors, Nucl. Eng. Des. 187 (1) (1999) 47-69.

[2] N. Girault, S. Dickinson, F. Funke, A. Auvinen, E. Krausmann, Iodine behaviour under LWR accident conditions: lessons learnt from analyses of the first two Phebus FP tests, Nucl. Eng. Des. 236 (12) (2006) 1293-1308.

[3] N. Girault, L. Bosland, S. Dickinson, F. Funke, S. Güntay, L. Herranz, D. Powers LWR severe accident simulation: iodine behaviour in FPT2 experiment and advances on containment iodine chemistry, Nucl. Eng. Des. 243 (2012) $371-392$

[4] B. Clément, N. Hanniet-Girault, G. Repetto, D. Jacquemain, A. Jones, M. Kissane P. Von Der Hardt, LWR severe accident simulation: synthesis of the results and interpretation of the first Phebus FP experiment FPT0, Nucl. Eng. Des. 226 (1) (2003) 5-82.

[5] J. Birchley, et al., Phebus-FP: results and significance for plant safety in Switzerland, Nucl. Eng. Des. 235 (15) (2005) 1607-1633.

[6] P. March, et al., First results of the PHEBUS FPT3 test, in: 14th International Conference on Nuclear Engineering, Miami, Florida, USA, 2006.

[7] D. Jacquemain, et al., An overview of the iodine behaviour in the two first PHEBUS tests FPT-0 and FPT-1, in: OECD Workshop on Iodine Aspects of Severe Accident Management, Vantaa, Finland, 1999.

[8] D. Jacquemain, et al., Iodine behaviour in phebus FPT2, comparison with previous phebus test, in: 5th PHEBUS FP Technical Seminar, Aix en Provence, France, 2003.

[9] N. Hanniet-Girault, G. Repetto, FPT0 Final Report, 1999. IPSN report PH-PF IP/ 99/423.

[10] D. Jacquemain, S. Bourdon, A. de Bremaecker, M. Barrachin, FPT1 Final Report 2000. IRSN report PH-PF IP/00/479.

[11] A.C. Grégoire, et al., FPT2 Final Report, 2008. IRSN report DPAM/DIR-2008 272, PHEBUS PF IP/08/579.

[12] F. Payot, et al., FPT3 Final Report, 2011. IRSN Document PHEBUS PF IP/10/587.

[13] H.S. Rosenberg, J.M. Genco, D.L. Morrison, Fission Product Deposition and its Enhancement under Reactor Accident Conditions: Deposition on Containment System Surfaces, Report BMI-1865, Battelle Memorial Institute, Columbus, Ohio, United States, 1969.

[14] A.B. Aleksandrov, N.I. Ampelogova, M.A. Karaseva, V.G. Kritskii, N.G. Petrik, The effect of physicochemical conditions on the absorption of molecular iodine by protective varnish and paint coatings during accidents at a nuclear power station with a VVER-640 reactor, Therm. Eng. 42 (12) (1995) 991-996.

[15] A. Zoulalian, E. Belval-Haltier, Interaction between molecular iodine in gaseous phase and a coat of paint - influence of temperature, humidity, and hydrothermal treatment on iodine trapping kinetics, Nucl. Tech. 122 (1998) $196-210$.

[16] E. Belval-Haltier, P. Taylor, Iodine volatile species production from painted surfaces of a reactor containment during a severe accident, in: OECD Workshop on Iodine Aspects of Severe Accident Management, Vantaa, Finland, May 18-20, 1999, pp. 103-118.

[17] A. Zoulalian, E. Belval-Haltier, Interaction between molecular iodine in a gas phase and paints aged in a nuclear power plant, Nucl. Tech. 130 (2000) $362-371$.

[18] T. Nugraha, Interactions of $I_{2}$ with Paints under Condensing Steam Conditions, Thesis, University of Toronto, Canada, 2003.

[19] F. Funke, Data analysis and modelling of organic iodide production at painted surfaces, in: OECD Workshop on Iodine Aspects of Severe Accident Management, Vantaa, Finland, May 18-20, 1999, pp. 151-168.

[20] C. Marchand, Production d'iodures organiques à partir des surfaces peintes de l'enceinte de confinement d'un réacteur à eau pressurisée en situation accidentelle, Thesis, Université Paris XI, Orsay, France, 1997.

[21] D.J.R. Bouveresse, R.C. Pinto, L.M. Schmidtke, N. Locquet, D.N. Rutledge, Identification of significant factors by an extension of ANOVA-PCA based on multi-block analysis, Chemom. Intell. Lab. 106 (2) (2011) 173-182.

[22] S. Amat, N. Dupuy, J. Kister, D.N. Rutledge, Development of near infrared sensors: detection of influential factors by the AComDim method, Anal. Chim. Acta 675 (2010) 16-23.

[23] P. Harrington, B. de, N.E. Vieira, J. Espinoza, J.K. Nien, R. Romero, A.L. Yergey, Analysis of variance-principal component analysis: a soft tool for proteomic discovery, Anal. Chim. Acta 544 (2005) 118-127.

[24] R.C. Pinto, V. Bosc, H. Noçairi, A.S. Barros, D.N. Rutledge, Using ANOVA-PCA for discriminant analysis: application to the study of mid infrared spectra of Carraghenan gels as a function of concentration and temperature, Anal. Chim. Acta 629 (2008) 47-55.

[25] C. Galant, B. Fayolle, M. Kuntz, J. Verdu, Thermal and radio-oxidation of epoxy coatings, Prog. Org. Coatings 69 (2010) 322-329.

[26] Use of an Alanine-electron Paramagnetic Resonance Dosimetry System, 2002. ISO/ASTM no 51607.

[27] K. Farah, T. Jerbi, F. kuntz, A. Kovacs, Dose measurements for characterization of a semi-industrial cobalt-60 gamma-irradiation facility, Radiat. Meas. 41 (2) (2006), 201-2018.

[28] M. Hanafi, G. Mazerolles, E. Dufour, E.M. Qannari, Common components and specific weight analysis and multiple Co-inertia analysis applied to the coupling of several measurement techniques, J. Chemom. 20 (2006) 172-183.

[29] R. Korifi, S. Amat, C. Rebufa, V. Labed, D.N. Rutledge, N. Dupuy, AComDim as a multivariate tool to analyse experimental design application to $\gamma$-irradiated and leached ion exchange resins, Chemom. Intell. Lab. 141 (2015) 12-23.

[30] C.B.Y. Cordella, D. Bertrand, SAISIR: a new general chemometric toolbox, Trends Anal. Chem. 54 (2014) 75-82.

[31] S. Hassani, H. Martens, E.M. Qannari, M. Hanafi, A. Kohler, Chemom. Intell. Lab. 17 (2012) 42-53.

[32] M. Abramowitz, I.A. Stegun (Eds.), Handbook of Mathematical Functions, Dover $<\mathrm{x}>$, NewYork, NY, 1965.

[33] The critical value of the F-test, according to the alpha level and the degrees of freedom is available from the website: http://www.danielsoper.com/ statcalc3.

[34] F. Delor-Jestin, D. Drouin, P.-Y. Cheval, J. Lacoste, Thermal and photochemical ageing of epoxy resin - influence of curing agents, Polym. Deg. Stab. 91 (2006) 1247-1255.

[35] Y.-M. Pei, K. Wang, M.S. Zhan, W. Xu, X.-J. Ding, Thermal oxidative aging of DGEBA/EPN/LMPA epoxy system: chemical structure and thermal - mechanical properties, Polym. Deg. Stab. 96 (2011) 1179-1186.

[36] P. Musto, G. Ragosta, P. Russo, L. Mascia, Thermal - oxidative degradation of 
epoxy and epoxy Bismaleimide networks: kinetics and mechanism, Macromol. Chem. Phys. 202 (18) (2001) 3445-3458.

[37] Y. Ngono, Y. Marechal, Epoxy - amine reticulates observed by infrared spectrometry. II. Modifications of structure and of hydration abilities after irradiation in a dry atmosphere, J. Polym. Sci. Part B Polym. Phys. 38 (2000) 329-340.

[38] S. Meure, D.-Y. Wu, S. Furman, FTIR study of bonding between a thermoplastic healing agent and a mendable epoxy resin, Vib. Spectrosc. 52 (2010) 10-15.

[39] E. Sharmin, M.S. Alam, R.K. Philip, S. Ahmad, Linseed amide diom/DGEBA epoxy blends for coating applications: preparation, characterization, aging studies and coating properties, Prog. Org. coatings 170-179 (2010).

[40] R. Sengupta, A. Bandyopadhyay, S. Sabharwal, T.K. Chaki, A.K. Bhowimck, Polyamide - 6.6/in situ hybrid nanocomposites by sol-gel technique: synthesis, characterization and properties, Polymer 45 (2005) 3343-3354.

[41] D. Xiao, X. Cui, W. Li, D. Yan, Investigation on the brill transition of polyamide 618, Front. Chem. China 2 (1) (2007) 6-12.

[42] P. Jain, V. Choudhary, I.K. Varma, Effect of structure on thermal behavior of epoxy resins, Eur. Polym. J. 39 (2003) 181-187.

[43] A. Rivaton, L. Moreau, J.L. Gardette, Photo-oxidation of phenoxy resins at long and short wavelengts - I. Identification of the photoproducts, Polym. Degrad. Stab. 58 (1997) 321-332.

[44] A. Rivaton, L. Moreau, J.L. Gardette, Photo-oxidation of phenoxy resins at long and short wavelengts - II. Mechanisms of formation of photoproducts, Polym. Degrad. Stab. 58 (1997) 333-339.

[45] N. Longiéras, M. Debban, P. Palmas, A. Rivaton, J.L. Gardette, Degradation of epoxy resins under high energy electron beam irradiation: radio-oxidation, Polym. Degrad. Stab. 92 (2007) 2190-2197.

[46] S.G. Burnay, Radiation-induced changes in the structure of an epoxy resin, Radiat. PhyS. Chem. 16 (1980) 389-397.

[47] F. Djouani, Y. Zahra, B. Fayolle, M. Kuntz, J. Verdu, Degradation of epoxy coatings under gamma irradiation, Radiat. Phys. Chem. 82 (2013) 54-62.

[48] L. Audouin, V. Langlois, J. Verdu, J.C.M. De Bruijn, Role of oxygen diffusion in polymer ageing: kinetic and mechanical aspects, J. Mater. Sci. 29 (1994) $569-583$.

[49] K.T. Gillen, R.L. Clough, in: D.W. Clegg, A.A. Collyer (Eds.), Irradiation Effects on Polymers, Elsevier Applied Science, London (, 1991.
[50] C. Decker, F.R. Mayo, Aging and degradation of polyolefins. II. $\gamma$-initiated oxidations of atactic polypropylene, J. Polym. Sci. Part A Polym. Chem. 11 (1973) 2847-2877.

[51] L. Bosland, et al., Iodine-paint interactions during nuclear reactor severe accidents, Ann. Nucl. Energy 74 (2014) 184-199.

[52] P. Pal, T.N. Misra, Charge transfer complexes of polyenes: spectroscopic, dark and photoconductive studies, J. Phys. D Appl. Phys. 23 (2) (1990) 218-222.

[53] C.D. Bryan, et al., Charge-transfer complexes of 4-phenyl-1,2,3,5dithiadiazolyl and 4-Phenyl-1,2,3,5-diselenadiazolyl with iodine. Preparation and solid-state characterization of [PhCN2E2]3[I3] (E = S, Se) and [PhCN2S2] [I3], Chem. Mater. 6 (4) (1994) 508-515.

[54] M.S. Refat, et al., Chemical and physical investigations on the charge transfer interaction of organic donors with iodine and its application as nontraditional organic conductors, J. Mol. Struct. 1074 (2014) 27-32.

[55] R. Kumara, A.J. Adaikala Baskar, V. Kannappanc, D. RoopSingh, Acoustical and spectroscopic investigation of charge transfer complexes of certain aromatic compounds with iodine in n-hexane at 303 K, J. Mol. Liq. 196 (2014) 404-410.

[56] S.Y. AlQaradawi, A. Mostafa, H.S. Bazzi, Charge-transfer complexes of 4methylpiperidine with $\sigma$ - and $\pi$-acceptors, Spectrochim. Acta Part A Mol. Biomol. Spectrosc. 135 (2015) 498-505.

[57] N.A. Al-Hashimi, Spectroscopic studies of the reaction of iodine with 2,3diaminopyridine, Spectrochim. Acta Part A Mol. Biomol. Spectrosc. 60 (2004) 2181-2184.

[58] M.S. Refat, S.M. Teleb, I. Grabchev, Charge-transfer interaction of iodine with some polyamidoamines, Spectrochim. Acta Part A Mol. Biomol. Spectrosc. 61 (2005) 205-211.

[59] M.S. Refat, et al., Synthesis and spectroscopic characterization on the triiodide charge transfer complex resulted from the interaction between morpholine as donor and iodine $\sigma$-acceptor, J. Saudi Chem. Soc. 14 (3) (2010) 323-330.

[60] J. Colombani, Experimental study of organic iodide volatilization from painted surfaces present in the containment during a severe accident, in: ERMSAR 2013, Avignon October 2-4, 2013.

[61] B. Simondi-Teisseire, N. Girault, F. Payot, B. Clément, Iodine behaviour in the containment in Phébus FP tests, Ann. Nucl. Energy 61 (2013) 157-169. 